\title{
Material model Johnson-Holmquist and its application in numerical analysis
}

\author{
Lucia Ondrušková ${ }^{1, *}$ and Prof. Ján Brodniansky ${ }^{1}$ \\ ${ }^{1}$ SUT in Bratislava, Faculty of Civil Engineering, Radlinského 11, 81005 Bratislava, Slovakia
}

\begin{abstract}
Model Johnson-Holmquist is commonly used for simulation of brittle materials under impacts and blast loading. In this paper is described its application to a model of a bolted connection in glass, when constant force is applied, and effect of two mesh sizings is compared.
\end{abstract}

\section{Introduction}

Glass in architecture nowadays is not only used as an infill of windows, but many other applications are common - balustrades, facades, roofs. There are also structures, where the glass elements are used as beams or columns. Therefore, the glass elements have to meet higher requirements for their load-bearing capacity. Safe behaviour of glass should be ensured during its fracture to prevent harm on human health or property. It can be proven by impact tests as was made in our laboratory $[1,2]$ or experimental mechanical analysis of glass windows subjected to dynamic tests and hard body impact were examined too in [3-6] Also, sufficient post-fracture load-bearing capacity for the necessary time, when one or more plies of glass are broken, should be ensured. The use of laminated glass is therefore needed. Another way to improve post-fracture performance of glass is application of reinforcement on a glass member [7].

Glass is a brittle material, there is no plasticization before failure of the glass element. The small flaws on the surface reduce the strength of glass due to high stress concentrations occurring at their tips when there is tension opening the crack. As the failure of the glass element can be sudden, the post-fracture state has to be taken into consideration in the design. In addition to experimental investigation [8] of behaviour of post-fracture phase of glass elements, there are also analytical $[9,10]$ and numerical models. In numerical analysis, material model Johnson-Holmquist is commonly used for modelling crack propagation in brittle materials under impact actions or blast loads [11]. Generally, the post-fracture behaviour of the fully fractured laminated glass depends on the size and the shape of glass fragments, interlayer stiffness and its adhesion to glass and the type of supports. It is an important part of the design of glass structures and a reliable model of this state would be useful.

In this paper the application of the material model Johnson-Holmquist to a model of a bolted connection in glass is described and the effect of two mesh sizings is compared.

\footnotetext{
* Corresponding author: lucia.ondruskova@,stuba.sk
} 


\section{Material model Johnson-Holmquist}

Material model Johnson-Holmquist is used for modelling behaviour of brittle materials under large pressure, shear strain and high strain rate. It is widely used for simulating ballistic impacts and blast loads. There are two versions of this model - segmented version (JH-1) and continuous version ( $\mathrm{JH}-2)$.

The following description of material model version $\mathrm{JH}-2$ is made according to descriptions found in $[11,12]$.

The normalized equivalent strength is defined as:

$$
\sigma^{*}=\sigma_{i}^{*}-D^{*}\left(\sigma_{i}^{*}-\sigma_{F}^{*}\right)
$$

where $\sigma_{i}{ }^{*}$ is the normalized intact strength, given by:

$$
\sigma_{i}^{*}=A\left(P^{*}+T^{*}\right)^{n}\left(1+C \ln \left|\varepsilon^{*}\right|\right)
$$

$\sigma_{F}{ }^{*}$ is the normalized material strength at fracture, given by:

$$
\sigma_{F}^{*}=B\left(P^{*}\right)^{m}\left(1+C \ln \left|\varepsilon^{*}\right|\right)
$$

In the equations (1) - (3), $A, B, C, m, n$ are material constants, $P^{*}$ is the normalized pressure $\left(P^{*}=P / P_{H E L}, P-\right.$ actual pressure, $P_{H E L}-$ pressure at Hugoniot elastic limit), $T^{*}$ is the normalized maximum tensile hydrostatic pressure $\left(T^{*}=T / P_{H E L}, T-\right.$ maximum tensile hydrostatic pressure), $\varepsilon^{*}$ is the actual strain rate $\dot{\varepsilon}$ over the reference strain rate $\dot{\varepsilon_{0}}=1,0 \mathrm{~s}^{-1}$ $\left(\varepsilon^{*}=\varepsilon^{*} \varepsilon_{0}\right)$.

$D^{*}$ is the damage scalar $(0 \leq D \leq 1)$, given by:

$$
D^{*}=\Sigma \Delta \varepsilon_{p} / \varepsilon_{p}^{f}
$$

where $\Delta \varepsilon_{p}$ is the plastic strain during an integration cycle, $\varepsilon_{p}^{f}$ is the plastic strain to fracture under a constant pressure $P . \varepsilon_{p}^{f}$ is defined as :

$$
\varepsilon_{p}^{f}=D_{1}\left(P^{*}+T^{*}\right)_{2}
$$

where $D_{1}, D_{2}$ are material constants.

Hydrostatic pressure is given by :

$$
P=K_{1} \mu+K_{2} \mu^{2}+K_{3} \mu^{3}+\Delta P
$$

where $K_{l}, K_{2}, K_{3}$ are constants and $\mu$ is defined as:

$$
\mu=\rho / \rho_{0}-1
$$

where $\rho$ is the current density, $\rho_{0}$ is the initial density.

Following polynomial equations of state are used in software Ansys :

For compression $-\mu>0$ :

$$
p=A_{1} \mu+A_{2} \mu^{2}+A_{3} \mu^{3}+\left(B_{0}+B_{1} \mu\right) p_{0} e
$$

For tension $-\mu<0$ :

$$
p=T_{1} \mu+T_{2} \mu+B_{0} p_{0} e
$$

where $e$ is the internal energy per unit of mass. 


\section{The numerical model of bolted connection in glass}

A 3D model of bolted connection in glass was created in the module Explicit Dynamics of the software Ansys. It consisted of a glass element with thickness $10 \mathrm{~mm}$, steel bolt of diameter $16 \mathrm{~mm}$ and aluminium bushing thick $2 \mathrm{~mm}$. Geometry of the model is pictured in Figure 1.

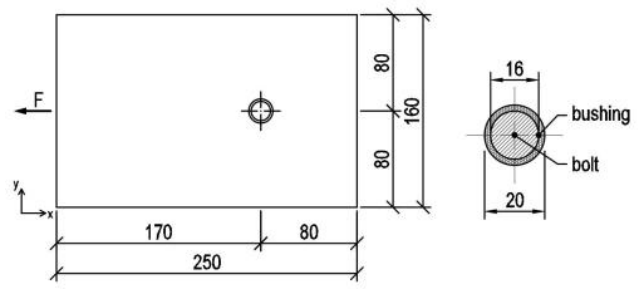

Fig. 1. Geometry of the glass element and detail of bolt and bushing.

Steel and aluminium were defined by density, Young's modulus and Poisson's ratio - as linear elastic materials. Density of steel was defined by value $7850 \mathrm{~kg} / \mathrm{m}^{3}$, Young's modulus of steel $210000 \mathrm{MPa}$ and Poisson's ratio 0,3. Density of aluminium was $2700 \mathrm{~kg} / \mathrm{m}^{3}$, Young's modulus $70000 \mathrm{MPa}$ and Poisson's ratio 0,3. Input values for the material model Johnson Holmquist for glass were adopted from the material library of Ansys. Used values can be found under the name FLOATGLASS and originate from [8]. Additionally, failure of material was defined by principal stress failure. Maximum tensile stress was defined as 45 $\mathrm{MPa}$. Maximum shear stress was defined as $500 \mathrm{MPa}$, which is only an estimate, because exact value wasn't found in literature. Then in analysis setting erosion control was set to material failure.

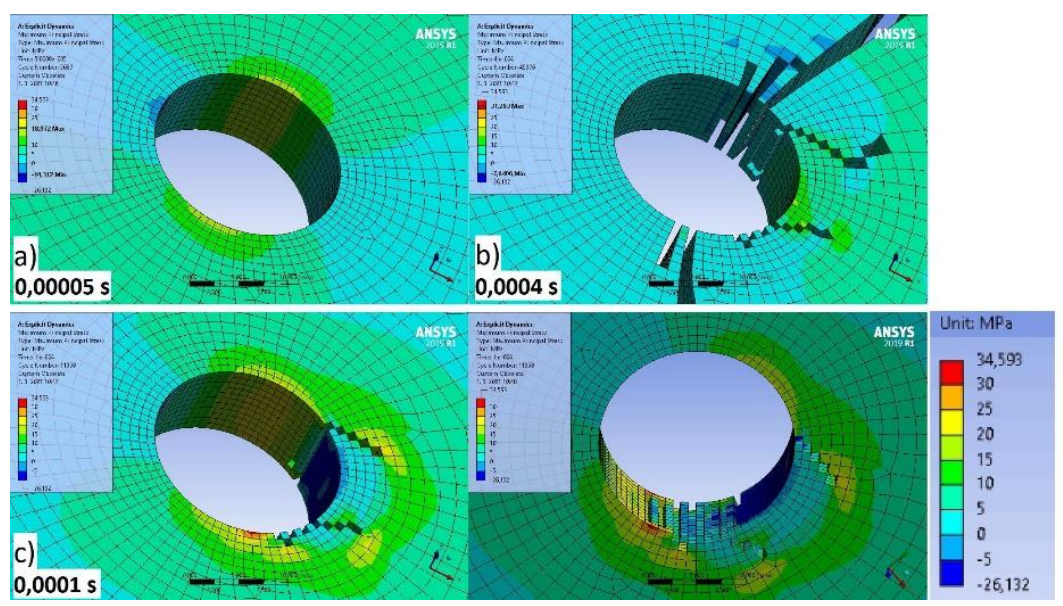

Fig. 2. Crack propagation in glass (DAMAGEALL).

Meshing of steel bolt and aluminium bushing was in both models the same. Size of elements was set to $2 \mathrm{~mm}$ and their circumference was divided to 40 elements. Meshing of glass in the first model (Model 1) within the radius $80 \mathrm{~mm}$ of the centre of the bolt was set to $2 \mathrm{~mm}$. Size of the mesh of the rest of the glass was set to $3 \mathrm{~mm}$. Hole circumference was divided to 80 
elements. In the second model (Model 2), meshing of the glass within the radius $80 \mathrm{~mm}$ of the centre of the bolt was set to $1 \mathrm{~mm}$ and size of elements of the rest of the glass was set to $1,5 \mathrm{~mm}$. Division of the circumference of the glass was the same -80 elements.

Contacts between bolt - bushing, bushing - glass was defined as rough, where surfaces are free to separate without resistance, but sliding is restricted. In reality, there is friction between components.

The constant force 7,5 kN was applied on the front surface of the glass and fixed support was assigned to the shear plates of the bolt. End time was set to $0,001 \mathrm{~s}$.

\subsection{Results}

The crack growth is depicted in Fig. 2. First cracks in both models appeared in the time $0,0001 \mathrm{~s}$ in the place where the bolt is pressing in the glass. In the $0,00015 \mathrm{~s}$ transverse cracks started to form.

In the Model 1 the transverse cracks started near the places where highest maximum principal stresses and erosion of few elements previously appeared (Fig. 3). They reached the edges of the glass in the time $0.0002 \mathrm{~s}$. In the next steps only small cracks in the direction perpendicular to the direction of force appeared on the sides of the hole, but there was no further growth of these cracks. After the time 0.0004 s no new cracks were created.

In the Model 2 the transverse cracks also started near the places of previous highest maximum principal stress and erosion of elements. Besides, in the time $0.00015 \mathrm{~s}$ one of the initial cracks started to propagate to the edge. The bottom transverse crack and the propagating initial crack reached the edges in the time $0.0002 \mathrm{~s}$. The upper transverse crack reached the edge in the time $0.0003 \mathrm{~s}$. There was also formation of small cracks near the transversal cracks in similar manner as in the Model 1. Also the middle initial crack showed a propagation from $0.00025 \mathrm{~s}$ to $0.00035 \mathrm{~s}$.

It was expected that the first cracks emerge from the location of highest maximum principal stress (see Fig. 3a). This expectation was not fulfilled. As there was no experiment, there is no experimental data to compare with the numerical models. The tensile strength of glass is governed by the small surface flaws and the critical flaw does not have to be in the place of maximum principal stress. From the point of view of the size of the fragments the results can be considered realistic, as the glass was broken into large fragments typical for annealed glass. 


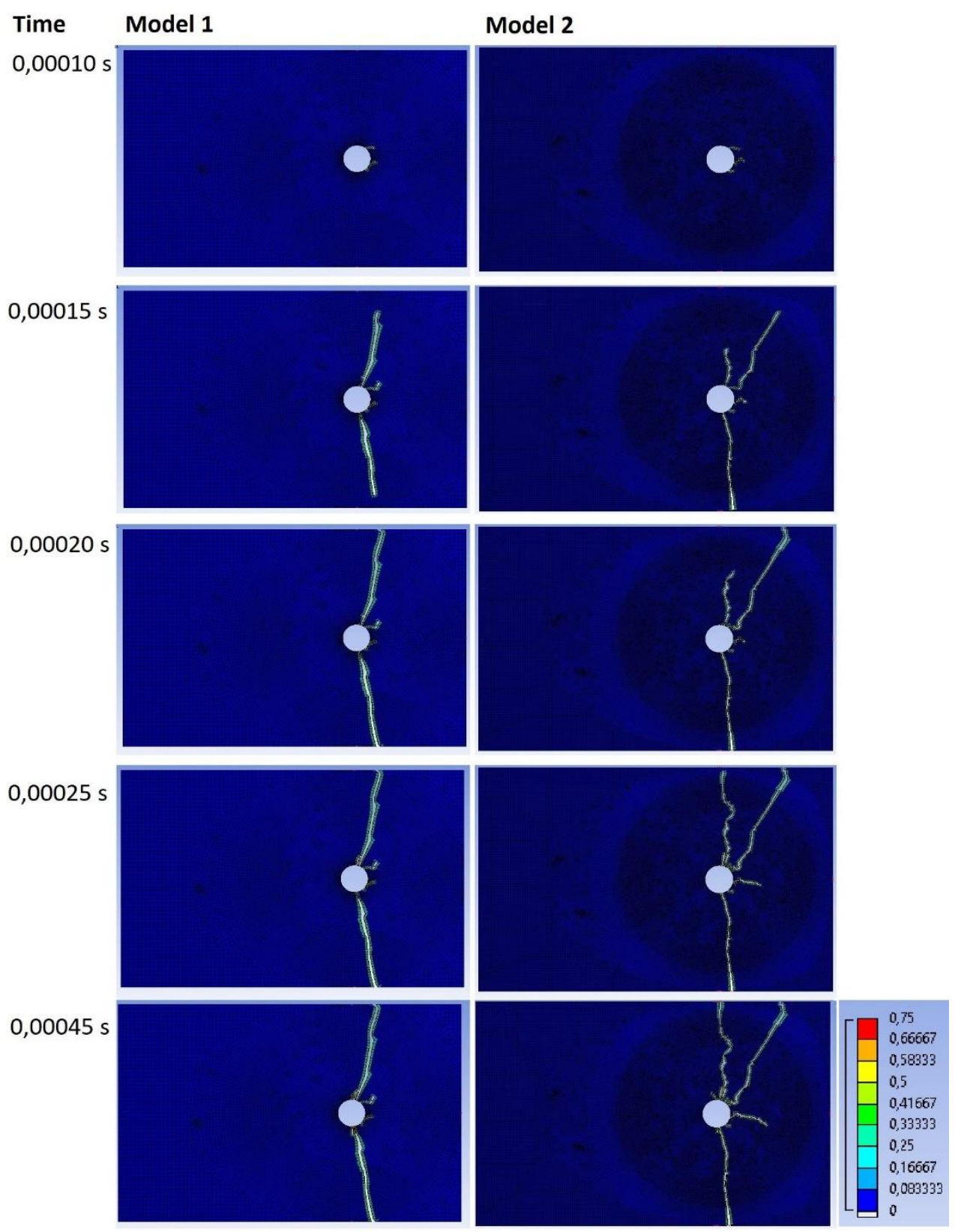

Fig. 3. Maximum principal stress - detail of the hole in the glass. 


\section{Conclusion}

The application of material model Johnson-Holmquist to a bolted connection in glass showed realistic results in terms of size of fragments of glass. The use of finer mesh led to growth of more cracks.

However, for point supported glass structures the use of heat strengthened or thermally toughened glass due to high stresses is needed. In these types of glass the residual stresses improving the strength of glass are introduced via heat treatment. Their fracture pattern is different from annealed glass. The question is, in what way apply the material model Johnson-Holmquist to heat strengthened and thermally toughened glass, or if there are more suitable models.

The authors would like to express thanks to the Grant agency of the Ministry of Education, Science, Research and Sports of the Slovak Republic for providing a grant from the research program VEGA Nr.1/0388/19 - Analysis and synthesis of the influence of the service conditions to line and thin- walled structures.

\section{References}

1. L. Balcierák et al., Advances and trends in engineering sciences and technologies II, 39 (2017)

2. J. Brodniansky, L. Balcierák, T. Klas, Brodniansky, Experimental pendulum tests of laminated and float glass plates. Interfaces - architecture, engineering, science - IASS (2017) 3. L. Figuli, D. Papan, Z. Papánová, C. Bedon. Smart Structures and Systems 27(2):365378. (2021) DOI: 10.12989/sss.2021.27.2.365

4. L. Figuli, Erdelyiova, R.; Papan, D. et al. MATEC web of conferences 313 (2020)

5. D. Papan, Papanova, Z.; Figuli, L. MATEC web of conferences 313 (2020)

6. Z. Papanova, Papan, D. 2020. MATEC web of conferences 313 (2020)

7. M. Slivanský, Slovak J. of Civ. Eng., 20, 21 (2012)

8. C. Zhao, J. Yang, X. Wang, I. Azim, Constr. Build. Mater., 224, 996 (2019)

9. S. J. Bennison, I. Stelzer, Glass Performance Days (2009)

10. L. Gallupi, G. Royer-Carfagni, Compos. Part B, 147, 227 (2016)

11. X. Zhang, H. Hao, G. Ma, Int. J. Impact Eng., 77, 108 (2015)

12. M. Štiglic, Optimálny návrh konštrukcií s uvážením jedostranných väzieb - Diz. práca (2015)

13. T. J. Holmquist, G. R. Johnson, 15th International Symposium on Ballistics (1995) 